\title{
Lavado traqueobrônquico auxiliado por endoscópio rígido ou por tubo endotraqueal em cães
}

\author{
Tracheobronchic washing in dogs by means of rigid endoscopy or endotracheal tube
}

\author{
Paula Cristina Basso ${ }^{\mathrm{I}^{*}}$ Heloísa Helena Alcântara Barcellos ${ }^{\mathrm{II}}$ \\ Maurício Veloso Brun ${ }^{\mathrm{II}}$ Laura Beatriz Rodrigues ${ }^{\mathrm{III}}$ Carlos Eduardo Bortolini ${ }^{\mathrm{I}}$ \\ Luciane Melatti ${ }^{I}$ João Francisco Scalco Neto ${ }^{I}$ Paulo Vinícius Bastiani ${ }^{I}$ \\ Stella de Faria Valle ${ }^{\mathrm{I}}$ Luciana Ruschel dos Santos ${ }^{\mathrm{III}}$
}

\section{RESUMO}

Com o objetivo de se avaliarem os resultados do uso de endoscopia rígida e da técnica por tubo endotraqueal de colheita de líquido traqueobrônquico, foram utilizados 28 cães, errantes ou domiciliados, distribuídos em dois grupos. Nos cães do grupo 1, aplicou-se a técnica de lavado traqueobrônquico em 14 cães, sendo sete sadios e sete com sinais clínicos respiratórios. Nos do grupo 2, utilizou-se a mesma técnica, entretanto com endoscopia rígida, em sete cães sadios e em sete cães com sinais clínicos de doença respiratória. Os dados evidenciaram que o procedimento utilizando-se endoscópio rígido resultou em menor volume de solução infundida e em maior porcentagem de solução recuperada. Não houve diferença significativa quanto ao tempo de duração da execução da técnica. A contagem bacteriana foi mais alta nas amostras coletadas por endoscópio rígido, porém não houve diferença significativa na contagem de células nucleadas totais. Portanto, o uso da endoscopia rígida para colheita de líquido traqueobrônquico mostrou-se mais vantajosa do que a técnica convencional utilizando-se o tubo endotraqueal, pois fornece imagens das vias aéreas e permite acompanhamento visual da lavagem.

Palavras-chave: lavagem traqueobrônquica, tubo endotraqueal, endoscopia rígida, cão.

\section{ABSTRACT}

The present study aimed to evaluate the results of rigid endoscopy and endotracheal tube techniques for collecting tracheobronchic fluid from dogs. Twenty eight erratic or housed dogs, were allocated into to two groups. In group 1 , tracheobronchic washing was applied to seven healthy dogs and seven dogs with clinical signs of respiratory disease. In group 2, seven healthy and seven dogs with respiratory disease were submitted to endo-bronchial washing by rigid endoscopy.
Using rigid endoscopy, a lower volume was introduced but a higher percentage of washing fluid was recovered. There was no difference regarding the time necessary to perform both techniques. Bacterial counts were higher in samples collected by rigid endoscopy, but there was no difference in total nucleated cell counts from these samples. Thus, the use of rigid endoscopy to collect tracheobronchic fluid was found to be advantageous when compared to the conventional technique using endotracheal tube.

Key words: tracheobronchic wash, endotracheal tube, rigid endoscopy, dogs.

\section{INTRODUÇÃO}

O aparelho respiratório é um dos sistemas orgânicos mais expostos a fatores de agressão externa, em função do seu contato direto com o meio ambiente. As afecções pulmonares representam grande parte do atendimento clínico de rotina em cães, devido ao alto índice de doenças infecto-contagiosas de características clínicas respiratórias nessa espécie (COHN, 2002). A radiografia torácica é, sem dúvida, o exame complementar mais utilizado nessas afecções, pois se constitui em um método não invasivo e de custo acessível. Contudo, o exame radiográfico torácico fornece padrões de alterações algumas vezes inespecíficos, limitando o diagnóstico definitivo (NORRIS et al., 2002). Dessa forma, o lavado broncoalveolar surge como exame complementar importante, fornecendo dados citológicos e

\footnotetext{
IPrograma de Pós-graduação em Medicina Veterinária (PPGMV), Centro de Ciências Rurais (CCR), Universidade Federal de Santa Maria (UFSM), Santa Maria, RS, Brasil. Rua Henrique Dias, 125/102, Centro, 97010-220, Santa Maria, RS, Brasil. E-mail: paula.basso@bol.com.br.*Autor para correspondência.

IIDepartamento de Clínica de Pequenos Animais, Faculdade de Medicina Veterinária e Agronomia (FMVA), Universidade de Passo Fundo (UPF), Passo Fundo, RS, Brasil.

IIIDepartamento de Microbiologia, FMVA, UPF, Passo Fundo, RS, Brasil.
} 
microbiológicos de brônquios, bronquíolos e alvéolos, que permitem uma melhor definição do distúrbio respiratório (HAWKINS et al., 2006).

A broncoscopia é um excelente método para a obtenção de lavado broncoalveolar, porém há necessidade de equipamento específico, e o tamanho do animal deve permitir a introdução do broncoscópio além do brônquio principal (ROUDEBUSH, 1990; JOHNSON, 2001). Para a avaliação broncoscópica do sistema respiratório, pode ser utilizado tanto o broncoscópio flexível como o rígido (HAAGEN, 1985). A técnica resume-se na introdução de um tubo endotraqueal, inserindo-se um broncoscópio de fibra óptica pelo tubo, o que possibilita a visibilização da traquéia e dos brônquios principais. Cerca de $2 \mathrm{ml} \mathrm{kg}^{-1}$ de solução fisiológica são infundidos e imediatamente aspirados pelo canal de sucção (JOHNSON \& McKIERNAM, 1995; COWELL et al., 1999).

$\mathrm{Na}$ indisponibilidade de um broncoscópio, pode-se obter o lavado broncoalveolar por meio de tubo endotraqueal (HAWKINS \& BERRY, 1999). Nessa técnica, o animal é colocado em decúbito lateral ou dorsal e, após a sua intubação e a inflação do balonete, é acoplado um adaptador de seringa na extremidade do tubo endotraqueal. Três alíquotas de fluido devem ser

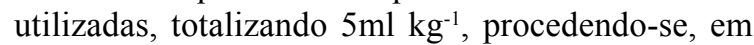
seguida, à aspiração imediata com a mesma seringa, até que não se obtenha mais fluido (COWELL et al., 1999).

A técnica de colheita do fluido do lavado broncoalveolar por meio de broncoscopia flexível leva vantagem sobre a técnica tradicional por permitir a visibilização das estruturas do aparelho respiratório e detectar possíveis alterações morfológicas, além de permitir a visão direta da colheita em locais mais específicos e a obtenção de biópsia do trato respiratório (JOHNSON, 2001; PASSOS et al., 2004).

No entanto, em muitas instituições, ainda existe a indisponibilidade do broncoscópio flexível. Nesse contexto, o presente artigo tem como objetivo comparar as vantagens e desvantagens da técnica experimental de colheita do fluido traqueobrônquico guiada por endoscopia rígida com a técnica convencional, em que se utiliza apenas tubo endotraqueal. Para isso, procurar-se-á avaliar o volume de líquido infundido, a porcentagem de líquido recuperado, o tempo de duração para execução de cada técnica e as características dos líquidos coletados por ambas as técnicas em animais sadios e com sinais clínicos respiratórios.

\section{MATERIAL E MÉTODOS}

Foram utilizados 28 cães, 17 fêmeas e 11 machos, domiciliados e/ou errantes, de raças e idades variadas, provenientes da região de Passo Fundo (RS). Quatorze cães formaram o grupo controle (Grupo 1), sete sadios (G1A) e sete com doença respiratória (G1B), os quais foram submetidos à técnica tradicional de colheita de lavado traqueobrônquico por meio de tubo endotraqueal. Os cães restantes formaram o grupo experimental (Grupo 2) e foram submetidos à técnica de colheita de lavado traqueobrônquico guiada por endoscópio rígido, sendo sete sadios (G2A) e os demais com doenças respiratórias (G2B). O peso corporal médio dos cães do G1 foi de $10,19 \pm 5,11 \mathrm{~kg}$ e o do $\mathrm{G} 2$ foi de $14,07 \pm 5,33 \mathrm{~kg}$.

Para a lavagem traqueobrônquica com tubo endotraqueal (Grupos 1A e 1B), os animais foram submetidos a jejum alimentar de 12 horas e foram prémedicados com maleato de acetilpromazina $0,2 \%$ $\left(0,05 \mathrm{mg} \mathrm{kg}^{-1}, \mathrm{IM}\right)$ e sulfato de morfina $\left(0,5 \mathrm{mg} \mathrm{kg}^{-1}, \mathrm{IM}\right)$. Após 15 minutos, foram induzidos com tiopental sódico $\left(12 \mathrm{mg} \mathrm{kg}^{-1}, \mathrm{IV}\right)$. Para a manutenção anestésica, foram administradas sucessivas doses do anestésico injetável, conforme a necessidade. Durante todo o procedimento, manteve-se canulação venosa com infusão de solução fisiológica, na velocidade de $10 \mathrm{ml} \mathrm{kg}^{-1} \mathrm{~h}^{-1}$. Cinco minutos antes da colheita do líquido, foi fornecido oxigênio a $100 \%$ via máscara facial, a fím de se evitar a ocorrência de hipóxia por hipoventilação transitória. Os cães foram posicionados em decúbito esternal e, com o auxílio de um laringoscópio, foi introduzida uma sonda gástrica número 12 ou 20 no interior da traquéia, sendo o tamanho da sonda associado ao peso corporal do animal. Tal sonda foi posicionada até a região anterior à bifurcação da traquéia, estimada externamente pelo quarto espaço intercostal. Foram infundidos, com seringas de $20 \mathrm{ml}$, de 5 a $13 \mathrm{ml} \mathrm{kg}^{-1}$ de solução de $\mathrm{NaCl}$ $0,9 \%$ estéril. Após a infusão, foram realizadas sucessivas aspirações do líquido com seringa de $60 \mathrm{ml}$. Terminado o procedimento, os animais receberam suplementação de oxigênio por 15 minutos e foram medicados com furosemida $2 \mathrm{mg} \mathrm{kg}^{-1}$, via intravenosa. Para a técnica de lavagem traqueobrônquica guiada por endoscópio rígido (Grupo 2A e 2B), os cães foram submetidos às mesmas tranqüilização e anestesia citadas acima. $\mathrm{O}$ procedimento de acesso à luz traqueal foi similar ao descrito anteriormente, no qual foi empregada uma sonda gástrica estéril número 12 , introduzida através do traqueotubo, mantendo-se o animal em decúbito ventral. Em seguida, foi retirado o traqueotubo e introduzido no interior da traquéia um endoscópio rígido de $10 \mathrm{~mm}$ e zero graus, acoplado a um sistema de vídeo. Após se posicionar a sonda anteriormente a bifurcação da traquéia, foram infundidos de 1 a $2 \mathrm{ml} \mathrm{kg}^{-1}$ de $\mathrm{NaCl}$ 0,9\%. Posteriormente, foram realizadas sucessivas aspirações do líquido com seringas de $60 \mathrm{ml}$. Os cuidados pós-procedimento foram similares aos empregados nos grupos 1A e 1B. 
Para a análise citológica, o fluido traqueobrônquico de todos os animais foi acondicionado em tubos de ensaio com EDTA(Etileno diamino tetra acetato de sódio). Posteriormente, foi realizada a contagem total de células nucleadas em câmara de Newbauer. Para o diferencial celular as amostras foram centrifugadas e do sobrenadante foi realizado um esfregaço, o qual foi corado com DiffQuick.

As amostras destinadas à cultura bacteriana foram acondicionadas em frascos estéreis, sendo posteriormente plaqueados $10 \mu \mathrm{l}$ em ágar MacConkey, manitol e ágar sangue. Todas as placas foram incubadas por $24 \mathrm{hs}$, a $37^{\circ} \mathrm{C}$, realizando-se, após isso, a primeira leitura quantitativa. As colônias suspeitas foram submetidas á coloração de Gram e a provas bioquímicas confirmatórias.

As variáveis de medida analisadas nos 28 cães para se compararem as técnicas foram duração do procedimento de colheita, volume de solução fisiológica infundida por quilograma corporal e porcentagem de fluido traqueobrônquico recuperado. Para se comparar a eficácia das técnicas sobre os animais com e sem doença respiratória, foi analisada a contagem de células nucleadas totais e a contagem de unidades formadoras de colônias por mililitro $\left(\mathrm{UFC} \mathrm{ml}{ }^{-1}\right)$ de fluido traqueobrônquico coletado. Os dados foram analisados estatisticamente por teste- $\mathrm{T}$, considerandose as diferenças como significativas quando $\mathrm{P}<0,05$. Para a análise microbiológica e citológica quantitativa, foi constatado, pelo teste de Hartley, que as variâncias eram heterogenias, e por isso, os dados foram transformados em logaritmo.

\section{RESULTADOS E DISCUSSÃO}

Em todos os animais foi possível realizar o exame proposto. A ausência de diferença significativa na duração de ambas as técnicas testadas $(\mathrm{G} 1=6,8 \pm 2,9$ minutos; $\mathrm{G} 2=8,5 \pm 3,3$ minutos) sugere que o fator tempo não é uma limitação para a execução do procedimento guiado por endoscopia rígida, o qual mostrou-se mais valioso do que a convencional, conforme posterior discussão.

A utilização da traqueoscopia rígida para a coleta do fluido traqueobrônquico demonstrou resultados próximos aos da broncoscopia flexível que possibilita amostras de lavado broncoalveolar mais precisas para pneumonia, pois permitiu visibilizar as estruturas anatômicas do trato respiratório e o local de colheita do fluido infundido. Isso possibilitou o recolhimento de amostras de fluido traqueobrônquico em quantidades significativas e de alto valor diagnóstico (Tabela 1), conforme descrito por JOHNSON (2001). No entanto, o endoscópio rígido permitiu a visibilização até a bifurcação da carina e o início dos brônquios principais, porém não foi possível identificarem-se os brônquios secundários e as suas divisões, conforme o que ocorre na broncoscopia flexível (RHA\& MAHONY, 1999).

A quantidade necessária de solução fisiológica infundida nos animais do G1 foi, em média, de $7,6 \pm 2,6 \mathrm{ml} \mathrm{kg}^{-1}$, ou seja, aproximadamente seis vezes maior que o volume necessário nos cães do grupo 2 $\left(1,2 \pm 0,4 \mathrm{ml} \mathrm{kg}^{-1}\right)$. Essa diferença altamente significativa pode ser atribuída à impossibilidade de visibilização morfológica das vias aéreas com a técnica por tubo endotraqueal, dificultando o procedimento de colheita. A redução na quantidade infundida é importante, haja vista que diminuiu o risco de desenvolvimento de hipóxia causado por edema alveolar e colapso alveolar durante o procedimento, conforme descreve ANDREASEN (2003). Além disso, observou-se que, quanto maior a quantidade de secreção presente nas vias aéreas dos cães doentes de ambas as técnicas, maior foi a quantidade de líquido utilizada para o lavado, pois é necessário fluidificarem-se as secreções para posterior aspiração. Esta foi a principal diferença da execução das técnicas em cães sadios e com tosse.

A porcentagem de fluido recuperada na técnica guiada por endoscópio rígido foi de $36,0 \pm 16,6 \%$, que se mostrou significativamente maior que a recuperada na técnica do tubo endotraqueal $(15,6 \pm 10,0 \%)$. Essa diferença de fluido recuperado ocorreu porque o endoscópio permitiu visibilizar-se exatamente o melhor local para se posicionar a extremidade da sonda gástrica durante a sucção, evitando dessa forma possíveis complicações associadas à infusão de grande quantidade de líquido (HAWKINS et al., 1999). Além disso, para a execução da técnica por endoscopia rígida, foi necessário-se retirar o traqueotubo para facilitar a entrada do endoscópio no lúmen traqueal. Esse procedimento implicou, em alguns cães, a perda de fluido infundido pela orofaringe, o que possivelmente não ocorreria se, durante a colheita, tivesse sido mantido o traqueotubo com o balonete inflado. Isso, tudo, não interferiu no resultado final da coleta.

A porcentagem média de fluido coletada na técnica convencional desse experimento foi relativamente mais baixa $(15,6 \pm 10,0 \%)$ em comparação a relatos prévios, nos quais recuperam-se em torno de 22,6\% (MELLO, et al., 2002). Entretanto, é preciso considerar-se que, nos cães do presente estudo, a posição dos animais não foi alterada para facilitar o retorno do fluido. Tal manobra iria necessitar de maior manipulação do paciente e poderia resultar na extubação da sonda para lavagem e, conseqüentemente, na contaminação orofaríngea das amostras de fluido traqueobrônquico, o que comprometeria a avaliação dos resultados da cultura bacteriana (COWELL et al., 1999). 
Tabela 1 - Relação dos dados de duração da execução das técnicas, do volume de $\mathrm{NaCl}$ 0,9\% infundido (ml) por quilograma de massa corporal, da porcentagem de fluido recuperado, da contagem de células nucleadas totais $/ \mathrm{ml}$, da contagem de UFC/ml e da conversão da contagem bacteriana para logaritmo, obtidos durante a execução das técnicas e das análises laboratoriais das amostras de lavagem traqueobrônquicas realizadas na Universidade de Passo Fundo (UPF), RS, Brasil (13/10/2006).

\begin{tabular}{|c|c|c|c|c|c|c|}
\hline Grupos & Duração (min) & $\begin{array}{l}\text { Volume infundido } \\
\qquad(\mathrm{ml} / \mathrm{kg})\end{array}$ & $\begin{array}{l}\% \text { de fluido } \\
\text { recuperado }\end{array}$ & $\begin{array}{l}\text { Contagem } \\
\text { celular/ml }\end{array}$ & $\mathrm{UFC} / \mathrm{ml}$ & $\log$ \\
\hline \multicolumn{7}{|l|}{ Grupo 1} \\
\hline 1 & 12 & 5,0 & 12,0 & 100 & $2,0 \times 10^{3}$ & 3,3 \\
\hline 2 & 6 & 5,0 & 10,0 & 250 & $1,6 \times 10^{3}$ & 3,2 \\
\hline 3 & 3 & 5,2 & 11,5 & 0 & $5,1 \times 10^{3}$ & 3,7 \\
\hline 4 & 5 & 5,4 & 14,3 & 550 & $2,5 \times 10^{4}$ & 4,4 \\
\hline 5 & 6 & 8,3 & 10,7 & 750 & $6,8 \times 10^{3}$ & 3,8 \\
\hline 6 & 9 & 6,6 & 25,0 & 50 & $7,0 \times 10^{4}$ & 4,8 \\
\hline 7 & 4 & 10,0 & 6,7 & 350 & $1,0 \times 10^{2}$ & 2,0 \\
\hline \multicolumn{7}{|c|}{ Grupo 1B } \\
\hline 1 & 13 & 13,0 & 45,0 & 450 & $1,6 \times 10^{4}$ & 4,2 \\
\hline 2 & 6 & 10,0 & 20,0 & 5200 & $4,6 \times 10^{4}$ & 4,7 \\
\hline 3 & 8 & 7,3 & 18,7 & 1200 & $3,0 \times 10^{5}$ & 5,5 \\
\hline 4 & 8 & 7,5 & 15,0 & - & $8,6 \times 10^{4}$ & 4,9 \\
\hline 5 & 6 & 5,0 & 16,0 & 1500 & $2,0 \times 10^{4}$ & 4,3 \\
\hline 6 & 4 & 10,6 & 10,6 & - & $3,3 \times 10^{4}$ & 4,5 \\
\hline 7 & 6 & 7,7 & 6,1 & 0 & $1,3 \times 10^{3}$ & 3,1 \\
\hline \multicolumn{7}{|c|}{ Grupo 2A } \\
\hline 1 & 7 & 1,0 & 48,0 & 0 & $1,5 \times 10^{4}$ & 4,2 \\
\hline 2 & 12 & 1,0 & 44,4 & 850 & $2,0 \times 10^{4}$ & 4,3 \\
\hline 3 & 13 & 1,0 & 40,0 & 1050 & $1,3 \times 10^{4}$ & 4,1 \\
\hline 4 & 9 & 1,0 & 18,2 & 50 & $1,9 \times 10^{4}$ & 4,3 \\
\hline 5 & 7 & 1,0 & 44,4 & 250 & $6,2 \times 10^{3}$ & 3,8 \\
\hline 6 & 6 & 2,0 & 13,1 & 50 & $<1,0 \times 10^{2}$ & 0,0 \\
\hline 7 & 4 & 1,0 & 40,0 & 250 & $1,2 \times 10^{5}$ & 5,1 \\
\hline \multicolumn{7}{|c|}{ Grupo 2B } \\
\hline 1 & 15 & 1,0 & 50,0 & 11050 & $3,0 \times 10^{4}$ & 4,5 \\
\hline 2 & 12 & 1,0 & 70,0 & 43350 & $2,6 \times 10^{5}$ & 5,4 \\
\hline 3 & 7 & 1,0 & 28,6 & 1600 & - & - \\
\hline 4 & 4 & 1,0 & 50,0 & 10050 & $6,8 \times 10^{5}$ & 5,8 \\
\hline 5 & 8 & 2,0 & 17,9 & 800 & $1,2 \times 10^{5}$ & 5,1 \\
\hline 6 & 8 & 1,0 & 20,0 & 450 & $1,7 \times 10^{4}$ & 4,2 \\
\hline 7 & 8 & 2,0 & 20,8 & 200 & $3,4 \times 10^{4}$ & 4,5 \\
\hline
\end{tabular}

Durante o procedimento de colheita do lavado traqueobrônquico com auxílio do endoscópio rígido, verificou-se que, logo após a introdução do instrumento, em todos os cães, ocorreu sondagem seletiva em um dos brônquios principais, fato que obrigava tracionar-se a sonda até altura anterior à bifurcação. Isso sugere que, como a técnica convencional não permite a visibilização, muito provavelmente a intubação também tornou-se seletiva, contudo isso é desvantajoso, haja vista que se pode lavar o brônquio que não está afetado na presença de doenças respiratórias, causando um resultado falso negativo (HAWKINS \& BERRY, 1999).

O'BRIEN (1970) defende o decúbito ventral como posição de escolha para a realização da broncoscopia em cães, pela sua facilidade de execução. No presente trabalho, essa observação foi seguida nos animais de ambos os grupos, sendo possível constatar que esse posicionamento tornou fácil a passagem e a movimentação da sonda e do endoscópio no G2. Segundo pesquisa realizada por MELLO et al. (2002), não existe diferença no fluido retornado entre os decúbitos lateral direito e dorsal, sugerindo que, independentemente do posicionamento, será obtida amostra satisfatória.

Ainda que DOMINGOS et al. (1997) relatem a utilização de anestesia inalatória para a manutenção durante a realização do exame broncoscópico, nesse experimento, procurou-se utilizar a anestesia injetável, pois não foi possível a passagem concomitante do 
endoscópio e do traqueotubo, o que poderia acarretar grande atrito e possível lesão da mucosa traqueal, ou, até mesmo, incapacidade de se realizar o exame pelas dimensões do endoscópio utilizado. Apesar de O’BRIEN (1970) relatar grande diversidade de fármacos empregados na anestesia para a colheita de lavado broncoalveolar, o protocolo utilizado nessa pesquisa mostrou-se eficiente, seguro e de baixo custo, fato também confirmado por PASSOS et al. (2004).

A indisponibilidade de endoscópio de calibre inferior durante a experimentação impossibilitou a execução da técnica endoscópica em cães com menos de $8 \mathrm{~kg}$, já que, nesses pacientes, tal instrumento obstruiria demasiadamente o lúmen traqueal, dificultando a passagem e/ou a movimentação da sonda no interior da traquéia, a manutenção de ventilação satisfatória, ou, até mesmo, impossibilitaria o exame. Essa limitação não foi observada na técnica de colheita através de tubo endotraqueal, que nesse trabalho pode ser aplicada em cães com massa corporal inferior a $2 \mathrm{~kg}$.

Durante o procedimento de lavagem traqueobrônquica guiada pelo endoscópio rígido, aproximadamente $30 \%$ dos cães sofreram complicações associadas a pequenas sufusões e equimoses na mucosa traqueal, em virtude da dificuldade de manipulação e passagem do instrumento no interior do órgão, que evoluíram substancialmente bem com o tratamento pós-operatório empregado. Tal condição provavelmente teria menor possibilidade de ocorrência caso fosse empregado endoscópio de menor diâmetro.

Os sinais clínicos observados após a lavagem traqueobrônquica consistiram de tosse e ruídos durante a auscultação, e foram mais acentuados nos cães submetidos à técnica que utiliza tubo endotraqueal, haja vista a maior quantidade de solução fisiológica injetada no interior do parênquima pulmonar. Tais sinais desapareceram espontaneamente dentro de 24 horas após o procedimento de lavagem.

Os resultados da cultura bacteriana quantitativa revelaram diferença significativa $(\mathrm{P}<0,05)$, comparando-se a contagem de unidades formadoras de colônias (UFC) por mililitro de fluido traqueobrônquico coletado dos animais do G2 $(4,6 \pm 0,6 \log )$ em relação aos do G1 $(4,0 \pm 0,9 \log )$. Valores mais altos de contagem na técnica guiada por endoscópio rígido podem ser atribuídos ao menor volume de solução fisiológica infundida, refletindo na concentração das amostras obtidas, o que propicia maior possibilidade de crescimento bacteriano (PEETERS et al., 2000). Além disso, ficou evidente uma diferença significativa na quantidade de $\mathrm{UFC} \mathrm{ml}^{-1}$ entre os animais sadios $(3,6 \pm 1,3 \log )$ e os doentes $(4,7 \pm 0,7 \log )$, com maior contagem bacteriana naqueles enfermos, fato que pode sugerir a diferença entre colonização e infecção do trato respiratório (PEETERS et al., 2000). A contagem média de UFC ml-1 encontrada nas amostras de lavagem traqueobrônquica dos cães saudáveis (3,6log) está de acordo com PEETERS et al. (2000), os quais consideram valores acima de $1,7 \times 10^{3} \mathrm{UFC} \mathrm{ml}^{-1}$ $(3,2 \log )$ como crescimento bacteriano clinicamente relevante.

As bactérias isoladas foram semelhantes entre as duas técnicas testadas e em relação aos animais sadios e doentes, nos quais se constatou maior porcentagem de Haemophilus aphrophilus (25\%), Staphylococcus epidermidis (25\%) e Staphylococcus aureus (25\%), seguindo-se de Klebsiella pneumoniae (13,9\%), Pseudomonas aeruginosa $(8,3 \%)$ e, por último, Escherichia coli (2,8\%). Esses microorganismos estão de acordo com os isolados de aspirados transtraqueais realizados por ANGUS et al. (1997) na Universidade da Califórnia. No entanto, diferem na ordem de maior expressão, pois, para os mesmos autores, as bactérias da família Enterobacteriaceae foram isoladas mais comumente, ao passo que as de Staphilococcus tiveram menor significância.

Na análise citológica, ficou evidente que não ocorreu diferença entre a contagem de células

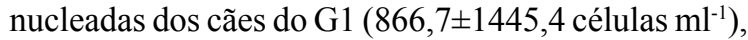

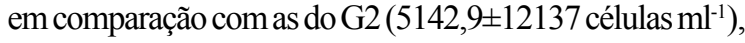
e que, em ambos os grupos, a contagem celular média

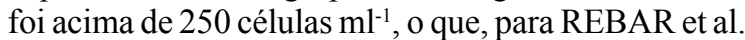
(1980), é crucial para se estabelecer a adequacidade da amostra. Isso indica que ambas as técnicas admitiram coleção de espécies representativas das vias aéreas. No entanto, dentro dos dois grupos, percebeu-se diferença significativa entre a contagem de células nucleadas totais dos animais doentes $(\mathrm{G} 1 \mathrm{~B}=$ 2087,5 $\pm 2121,5$ células $\mathrm{ml}^{-1} ; \mathrm{G} 2 \mathrm{~B}=9928,6 \pm 16292$ células $\left.\mathrm{ml}^{-1}\right)$ e sadios $\left(\mathrm{G} 1 \mathrm{~A}=256,2 \pm 277,0\right.$ células $\mathrm{ml}^{-1} ; \mathrm{G} 2 \mathrm{~A}=$ $357,1 \pm 420,7$ células $\mathrm{ml}^{-1}$ ), devido à intensa inflamação do trato respiratório nos cães enfermos.

Em relação à avaliação citológica, verificouse que as células predominantes nos animais saudáveis de ambos os grupos foram os macrófagos alveolares $(\mathrm{G} 1 \mathrm{~A}=71,8 \pm 13,9 \% ; \mathrm{G} 2 \mathrm{~A}=45,2 \pm 24,9 \%)$, condição previamente observada por ANDREASEN (2003). Na seqüência, vieram as células epiteliais cuboidais $(\mathrm{G} 1 \mathrm{~A}=$ $20,0 \pm 17,0 \%$; $\mathrm{G} 2 \mathrm{~A}=44,8 \pm 33,4 \%$ ), resultado que difere ao do autor supracitado, o qual descreve a ocorrência desse tipo celular em $1 \%$ em lavados broncoalveolares de cães hígidos. Esse achado indica que as amostras coletadas representam a lavagem de grandes vias aéreas (lavado traqueobrônquico) e não das porções profundas dos pulmões (MELLO et al., 2002). No G1, as médias de neutrófilos $(4,4 \pm 32,0 \%)$ e linfócitos $(1,2 \pm 2,2 \%)$ foram menores que no $\mathrm{G} 2(8,6 \pm 8,3$ e $0 \%$, respectivamente), estando dentro dos padrões de referências (HAWKINS et al., 2006).

Em contrapartida, os cães doentes do G1B e do G2B tiveram como células de maior ocorrência os 
neutrófilos segmentados $(\mathrm{G} 1 \mathrm{~B}=38,4 \pm 32,0 \%$; $\mathrm{G} 2 \mathrm{~B}=$ $58,0 \pm 29,2 \%$ ), apresentando-se degenerados em seis dos 14 cães doentes avaliados, o que sugere alteração nas vias aéreas, compatível com inflamação neutrofílica aguda (MELLO et al., 2002). Os outros tipos celulares encontrados foram macrófagos alveolares $(\mathrm{G} 1 \mathrm{~B}=$ $30,8 \pm 20,6 \% ; \mathrm{G} 2 \mathrm{~B}=32,7 \pm 16,2 \%$ ), células cuboidais $(\mathrm{G} 1 \mathrm{~B}=1,2 \pm 1,8 \% ; \mathrm{G} 2 \mathrm{~B}=9,6 \pm 15,9)$ e linfócitos $(\mathrm{G} 1 \mathrm{~B}=$ $4,4 \pm 4,0 \% ; \mathrm{G} 2 \mathrm{~B}=2,8 \pm 6,0 \%)$. Em três dos 14 cães, ficou evidente alto número de bactérias no esfregaço, sugerindo infecção bacteriana. Reações imunológica e de hipersensibilidade não foram identificadas, em virtude de a porcentagem de linfócitos e eosinófilos estarem dentro dos parâmetros normais, respectivamente (MELLO et al., 2002).

\section{CONCLUSÕES}

Sob as condições experimentais testadas, foi possível concluir-se que a colheita do fluido traqueobrônquico guiada por endoscópio rígido é exeqüível, de fácil realização e viável em instituições que dispõnham do equipamento. Essa técnica mostrase vantajosa em relação à técnica convencional com sonda endotraqueal, pois permite a visibilização do local da colheita, requer menor volume de fluido infundido, resulta em uma maior porcentagem de fluido recuperado, e requer o mesmo tempo de execução que a técnica por tubo endotraqueal, além de possibilitar amostragem representativa das vias aéreas para avaliação microbiológica e citológica.

\section{COMITÊ DE ÉTICA E BIOSSEGURANÇA}

O experimento foi aprovado pelo comitê de ética da Universidade de Passo Fundo (UPF) sob registro 050/2006 e seguiu as normas de bem-estar preconizadas pelo COBEA (Colégio Brasileiro de Experimentação Animal).

\section{REFERÊNCIAS}

ANDREASEN, C.B. Bronchoalveolar lavage. Veterinary Clinics of North America: Small Animal Practice, v.33, n.1, p.69-88, 2003.

ANGUS, J.C. et al. Microbiologycal study of transtracheal aspirates from dogs with suspected lower respiratory tract disease: 264 cases (1989-1995). Journal American Veterinary Medical Association, v.210, n.1, p.55-58, 1997.

BROWN, N.O. et al. Alveolar lavage in dog. American Journal of Veterinary Research, v.44, n.2, p.335-337, 1983.

COHN, L.A. Infectious diseases of the respiratory tract II, 2002. Capturado em 20 set. 2006. Online. Disponível na Internethttp://www.vin.com/Proceedings/ Proceedings.plx?CID $=$ wvc2002\&PID $=$ pr0093.

COWELL, R.L. et al. Transtracheal/bronchoalveolar washes. In: COWELL, R.L. et al. Diagnostic cytology and hematology of the dog and cat. St. Louis: Mosby, 1999. cap.13, p.159-173.

DOMINGOS, L.O. et al. Avaliação endoscópica das lesões nas vias aéreas superiores decorrentes da intubação endotraqueal em cães. Brazilian Journal of Veterinary Research and Animal Science, v.34, n.5, p.278-283, 1997.

HAAGEN, A.J.V.V. Bronchoscopy in small animal clinics: an analysis of the results of 228 bronchoscopies. Journal of American Veterinary Medical Association, v.21, n.4, p.521-526, 1985.

HAWKINS E.C; BERRY, C.R. Use of a modified stomach tube for bronchoalveolar lavage in dogs. Journal American Veterinary Medical Association, v.215, n.11, p.1635-1639, 1999.

HAWKINS, E.C. et al. Cellular composition of bronchial brushings obtained from healthy dogs and dogs with chronic cough and cytologic composition of bronchoalveolar lavage fluid obtained from dogs with chronic cough. Journal American Veterinary Medical Association, v.67, n.1, p.160-167, 2006.

JOHNSON, L. Small animal bronchoscopy. Veterinary Clinics of North America: Small Animal Practice, v.31, n.4, p.691-795, 2001.

JOHNSON, L.R.; McKIERNAM, B.C. Diagnosis and medical management of tracheal collapse. Seminars Veterinary Medical Surgery (Small Animal), v.10, n.2, p.101-108, 1995.

MELLO, M.F.V. et al. Cytologic analysis of bronchoalveolar lavage fluid collected through an endotracheal tube in dogs. Acta Scientiae Veterinariae, v.30, n.2, p.119-125, 2002.

NORRIS, C.R. et al. Thoracic radiography, bronchoalveolar lavage cytopathology, and pulmonary parenchymal histopathology: a comparison of diagnostic results in 11 cats. J Journal of American Veterinary Animal Hospital Association, v.38, n.4, p.337-345, 2002.

O'BRIEN, J.A. Bronchoscopy in the dog and cat. Journal American Veterinary Medical Association, v.156, n.2, p.213-217, 1970 .

PASSOS, R.F.B. et al. Viabilidade da inspeção traqueobrônquica, por videoendoscopia, em cães. Brazilian Journal of Veterinary Research and Animal Science, v.41, n.5, p.110,2004

PEETERS, D.E. et al. Quantitative bacterial cultures and cytological examination of bronchoalveolar lavage specimens in dog. Journal of Veterinary Internal Medicine, v.15, n. 1, p.534-541, 2000.

REBAR, A.H. et al. Bronchopulmonary lavage cytology in the dog: normal findings. Veterinary Pathology, v.17, n.3, p.294304, 1980 .

RHA, J.Y.; MAHONY, O. Bronchoscopy in small animal medicine: indications, instrumentation, and techniques. Clinical Techniques in Small Animal Practice, v.14, n.4, p.207-212, 1999.

ROUDEBUSH, P. Tracheobronchoscopy. Veterinary Clinics of North America: Small Animal Practice, v.20, n.5, p.1297-1314, 1990.

Ciência Rural, v.38, n.3, mai-jun, 2008. 